\title{
Capgras syndrome of time: A case study
}

\author{
Aziz VM and Rodgers S \\ Devon Partnership NHS Trust Mental health service in Exeter, England, UK
}

\section{Introduction}

Capgras Syndrome (named after Joseph Capgras), is of the rare delusional misidentification syndromes, along with Fregoli syndrome, syndrome of intermetamorphosis and syndrome of subjective doubles [1]. The patient with Capgras syndrome believes someone close to them has been replaced by an imposter. Capgras syndrome has been described in the literature, but there a few case studies of Capgras syndrome of time [2]. This case study will describe a patient who presented with Capgras syndrome of time as part of her psychotic depression.

\section{Case presentation}

The patient is a 69-year-old retired secretary who lives alone independently. She was admitted under section 2 of the mental health act following a short period of increasing confusion, anxiety and suicidal ideation.

She has a previous diagnosis of bipolar affective disorder, previously unmedicated and had not previously been admitted under mental health services. She also has a diagnosis of atrial fibrillation and hypertension and is on treatment for these.

She is one of four siblings, the only daughter to a civil servant and social worker. She went to boarding school aged 10 and left with 3 A levels. She worked for a building firm, in a secretarial role before retiring. She has a very active social life and is very involved in the local community. She recently ended a long term, but clandestine relationship. She does not have any children.

She presented with nihilistic delusions, delusions of guilt and paranoia, along with other features of a depressive episode including poor concentration, disturbed sleep, psychomotor retardation.

She believed staff were locking patients on the ward without food or water. The patients would then eat each other.

She reported the district general hospital from where she had been transferred had been destroyed; she was responsible. She described then that the world outside the ward had been destroyed. When challenged, she replied that the ward was stuck in a time warp, the rest of the world was in the future, and was already destroyed.

\section{Management and outcome}

She was investigated for any organic causes. Blood tests including renal function, full blood count, B12, folate, TSH and prolactin were all within normal limits. The patient was noted to have mildly deranged liver function, and an ultrasound was performed which showed gallstones only. Her liver function subsequently normalised. An ECG confirmed she was in atrial fibrillation. The patient scored 25/30 on a MOCA and 10 on a Hamilton Depression Rating Scale.
She was treated with mirtazapine and olanzapine and had a course of 9 sessions of ECT. She has responded well to treatment and has no persisting psychotic symptoms. She is unable to remember much of her delusional symptoms, including her delusion around the ward being in a time warp.

\section{Discussion}

Capgras syndrome of time has been reported with both organic and functional disorders - including schizophrenia and affective psychoses. It is most commonly reported in females, initially it was thought to be a female only disorder when first described [3].

Capgras syndrome is less frequently associated with bipolar disorder compared to schizophreniform disorders or organic disorders [4]; so, making this patients presentation with Capgras syndrome of time very rare.

This patient displayed Capgras syndrome of time with her delusions of being in a time warp on the ward. She believed the outside she could see was 'imposter' - this was really destroyed, and it is in the future - what she was seeing was in a time warp. She used this to explain how staff were able to come and go on the ward and there were other patients admitted on the ward.

This time warp is unlike some of the previously described Capgras syndrome of time, which include duplication of time, such as repeated days of the week and déjà vu phenomenon, such a reliving a Sunday daily.

Our patient was treated with olanzapine which has previously been reported to be very effective in treating Capgras syndrome [5]. However, treating the underlying depression also was important in resolution of the symptoms. It is not clear whether she is unable to remember this delusion as a result of her ECT treatment or as part of her illness and recovery.

One could argue that this delusion was almost like Cotard syndrome - she was dead, destroyed in the future, and this was time warp she was existing in. This patient provides a very interesting case of Capgras syndrome of time, with her distortion of the perception of time, in part explaining her nihilistic delusions that the world was destroyed.

\section{References}

1. Bhandari S (2012) Unusual psychiatric syndromes. Core Psychiatry. p 349-350.

2. Aziz VM, Warner NJ (2005) Capgras' Syndrome of Time. Psychopathology 38: 49-52. [Crossref]

${ }^{\star}$ Correspondence to: Aziz VM, Devon Partnership NHS Trust Mental health service in Exeter, England, UK, E-mail: victoraziz@doctors.org.uk

Received: November 02, 2019; Accepted: November 15, 2019; Published: November 20, 2019 
3. Merrin EL, Silberfarb PM (1976) The Capgras phenomenon. Arch Gen Psychiatry 33: 965-968. [Crossref]

4. Salvatore P, Bhuvaneswar C, Tohen M, Khalsa HM, Maggini C, et al. (2014) Capgras Syndrome in First-Episode Psychotic Disorders. Psychopathology 47: 261-269. [Crossref]
5. Vasileiadou M, Thomaidis G, Simitsi A, Krasanaki C. Evolving Acute Capgra's syndrome with psychotic mania and remission with standard olanzapine and valproate acid treatment. Case report. 19th World Congress of Psychiatry, General Hospital Thessaloniki, August 2019.

Copyright: (C2019 Aziz VM. This is an open-access article distributed under the terms of the Creative Commons Attribution License, which permits unrestricted use, distribution, and reproduction in any medium, provided the original author and source are credited. 